Check for updates

London

Cite this as: $B M J 2022 ; 376: 0473$

http://dx.doi.org/10.1136/bmj.0473

Published: 23 February 2022

\title{
It's time to trust NHS staff to do the right thing
}

\section{Chris Ham}

The NHS has been warned. The additional funding announced by the government comes with increased scrutiny. ${ }^{1}$ Reflecting both public and therefore political concerns, scrutiny will focus on clearing the care backlogs that have built up during the pandemic in line with targets set out in the elective recovery plan. $^{2}$

Michael Barber, who led work on the delivery of public services reform in Tony Blair's government, is advising Boris Johnson's government on how to do so. A delivery unit has been established in No.10 under Emily Lawson who led implementation of the successful NHS vaccination programme. Little information has been released about the unit, but if Barber's previous work is a reliable guide it will rely on regular reporting of progress with increased pressure to improve when performance falls short.

Leaders at every level of the NHS will be expected to demonstrate they are doing everything possible to hit the targets in line with established best practice. Management consultants have been hired at a cost of $£ 42$ million to support delivery of the elective recovery plan in a sign that national leaders believe that left to its own devices the NHS may struggle to do so. Failure to deliver will have consequences as the grip of the centre is tightened.

These measures will add to the heavy burden of regulation and reporting requirements under which the NHS already labours. They will ineluctably lead to an increased focus on what is measured with other priorities not covered by targets receiving less attention. The danger then is that the emphasis on delivery disempowers local leaders at best and results in gaming at worst as leaders seek to avoid being penalised or sacked when unable to deliver.

If improving patient care is always going to be a high priority for the public and politicians, what are the alternatives to service improvement being led from the top down? One of the lessons from how the NHS responded to the pandemic is that amazing things can happen when local leaders and clinical teams are trusted to make decisions. Services were reorganised at pace by increasing intensive care capacity, discharging patients from hospital to release beds for seriously ill patients, providing more care in people's homes, and embracing digital technologies-among many other innovations.

The pandemic also demonstrated the benefits of partnership working. Collaboration between general practices helped deliver the vaccination programme at scale and ensured that patients received routine care in safe settings; mutual aid between hospitals enabled effective use of scarce intensive care capacity and delivery of elective recovery when covid pressures permitted; and closer working between health and social care meant that patients were cared for in the right place through sharing of expertise and resources.

As the NHS and its partners continue work on recovery, politicians and national leaders must build on the positive experiences of the pandemic response and resist the instinct to take back control.

Accountability for how resources are used is a given, but should not be confused with micromanagement that becomes so overbearing as to eradicate the scope for local innovation. "Devolution and transparency," in which public reporting of performance data are a spur to improvement, should be given greater prominence.

Plans to establish integrated care systems (ICSs) as statutory bodies in England in July 2022 offer an opportunity to put these ideas into practice. The Department of Health and Social Care and NHS England have both committed to giving ICSs greater freedoms to take decisions appropriate to the needs of the populations they serve and to do so by working in partnership with local authorities, voluntary and community sector organisations, and others. A high priority should be to publish data on the performance of ICSs to enable local people to see how well they are being served.

ICSs should also support each other through sharing expertise and helping to spread the adoption and adaptation of best practices. At the formation of the NHS, Nye Bevan expressed an ambition to "universalise the best" but this has proved difficult to realise. Networking between ICSs and recognition of the value of peer support and challenge is long overdue. It is also likely to offer better value for money than continuing reliance on management consultants.

Scrutiny and oversight have had mixed success in the NHS and, to borrow from Einstein, the definition of insanity is doing the same thing over and over again and expecting different results. As David Oliver put it recently in The BMJ, NHS organisations “don't need central agencies telling them to create empty beds; they're engaged in a daily battle to do exactly this." "3 Why not try a different approach and trust staff to do the right thing?

Governing the Health and Care System in England: creating conditions for success by Chris Ham is published today by the NHS Confederation. ${ }^{4}$

Competing interests: $\mathrm{CH}$ was chief executive of The King's Fund from 2010 to 18

Provenance and peer review: not commissioned, not peer reviewed

Health Service Journal. Prepare for tighter grip from regulators, says Mackey https://www.hsj.co.uk/quality-and-performance/prepare-for-tighter-gripfrom-regulators-says-mackey/7031912.article

Coronavirus » Delivery plan for tackling the COVID-19 backlog of elective care https://www.england.nhs.uk/coronavirus/publication/delivery-planfor-tackling-the-covid-19-backlog-of-elective-care/ 


\section{OPINION}

3 Oliver D. David Oliver: Central diktats won't help more patients leave local hospitals. BMJ 2022;376:0246. doi: 10.1136/bmj.0246. pmid: 35140069

4 Ham C. Governing the Health and Care System in England: creating conditions for success. NHS Confederation. https://www.nhsconfed.org/publications/governing-health-and-care-systemengland 